\title{
Preferences and Paternalism
}

\section{On Freedom and Deliberative Democracy}

Rostbøll, Christian Fogh

Published in:

Political Theory

DOI:

10.1177/0090591704272351

Publication date:

2005

\section{Document version}

Publisher's PDF, also known as Version of record

Citation for published version (APA):

Rostbøll, C. F. (2005). Preferences and Paternalism: On Freedom and Deliberative Democracy. Political Theory, 33(3), 370-396. https://doi.org/10.1177/0090591704272351 


\title{
Political Theory
}

http://ptx.sagepub.com

\section{Preferences and Paternalism: On Freedom and Deliberative Democracy \\ Christian F. Rostbøll \\ Political Theory 2005; 33; 370 \\ DOI: $10.1177 / 0090591704272351$}

The online version of this article can be found at: http://ptx.sagepub.com/cgi/content/abstract/33/3/370

\author{
Published by: \\ (SAGE \\ http://www.sagepublications.com
}

Additional services and information for Political Theory can be found at:

Email Alerts: http://ptx.sagepub.com/cgi/alerts

Subscriptions: http://ptx.sagepub.com/subscriptions

Reprints: http://www.sagepub.com/journalsReprints.nav

Permissions: http://www.sagepub.com/journalsPermissions.nav 


\title{
MOVING PREFERENCES AND SITES IN DEMOCRATIC LIFE
}

\section{PREFERENCES AND PATERNALISM On Freedom and Deliberative Democracy}

CHRISTIAN F. ROSTBØLL

Columbia University

\begin{abstract}
This article discusses the relationship between the ideal of autonomous preference formation and the danger of paternalism in deliberative democratic theory. It argues that the aim of autonomous preference formation can and should be decoupled from a justification of paternalistic state action aimed at reshaping citizens' preferences. The problem of nonautonomous preference formation is rooted in the communication structure in which each and every one forms her preferences and hence cannot be solved by some paternalistically judging on others'behalf. The argument is based on a new formulation of the deliberative democratic ideal, which emphasizes and clarifies the multiple dimensions of freedom it incorporates.
\end{abstract}

Keywords: deliberative democracy; freedom; paternalism; preference formation; autonomy

itizens do not always know what is in their own best interest. Their political action and inaction often go contrary to what would be best for them. It would be better if they formed their political opinions and wills differently, more autonomously. Statements such as these underlie some important strands of deliberative democratic theory and are inevitably met with the charge of paternalism. The interesting thing is that both sides of this debate appeal to freedom, albeit to different dimensions of freedom. The deliberative democrat is concerned with the dimension of freedom that has to do with

AUTHOR'S NOTE: An earlier version of this essay was presented at the thirty-fourth annual meeting of the Northeastern Political Science Association, Providence, Rhode Island, November 7-9, 2002. For their comments, I wish to thank Jean Cohen, Jon Elster, Pablo Gilabert, Brent D. Lollis, Reidar Maliks, Don Moon, Stephen K. White, Elizabeth Wolff, and the anonymous reviewers for this journal.

POLITICAL THEORY, Vol. 33 No. 3, June 2005 370-396

DOI: $10.1177 / 0090591704272351$

(c) 2005 Sage Publications 
the autonomous formation of political preferences; the antipaternalist is concerned with the freedom to form one's own preferences without interference. To go beyond this opposition, we must develop a model of deliberative democracy that is normatively committed to multiple dimensions of freedom. The normative appeal of deliberative democracy is best understood in terms of the way it incorporates several dimensions of freedom. A clarification of this characteristic shows why such a theory actually supports skepticism toward paternalism. Thus, I intend to decouple deliberative democratic theory from the justification of paternalistic state action aimed at reshaping citizens' preferences.

The need for a clarification of the normative commitment to a wider theory of freedom is especially urgent if we see deliberative democracy as a critical theory, as I think we should. Critical theory is intrinsically linked to a multidimensional theory of freedom-because of its concern with emancipation from all forms of oppression - and committed to clarifying the standards in light of which social criticism is made. ${ }^{1}$ As critical theory, deliberative democracy should contribute to the analysis of which aspects of contemporary society limit our prospects for enjoying the multiple dimensions of freedom to which it is normatively committed. But it should also contribute to the investigation of whether it is possible to free ourselves from certain forms of oppression without creating new ones, as, for example, paternalism. It is this latter issue that is the main concern of this article. I argue that we can and should sever the close connection between the concern with autonomous preference formation and the justification of paternalism by means of a more complex account of the relationship between deliberative democracy and freedom.

Two dimensions of freedom are familiar, namely, political freedom and individual freedom, or the freedom of the ancients and that of the moderns. Deliberative democrats have attempted to reconcile these two dimensions. ${ }^{2}$ But, even if these attempts are judged to be successful, deliberative democrats still face another challenge. An important part of the critical edge of the theory of deliberative democracy is that it problematizes the status of the preferences people happen to have. It does not regard preferences and interests as brute facts that uncritically can serve as input to legitimate democratic decision making. It thematizes the possibility that preferences can be nonautonomously formed and that they can be unjustifiable to others in public deliberation. ${ }^{3}$ The first issue brings into the picture a third dimension of freedom, which has played a crucial role in the development of the theory of deliberative democracy. A main assumption in this development has been that the formation of preferences is endogenous to social conditions and political institutions. It is for this reason we should go beyond seeing the 
democratic process merely as one of aggregating preferences. But the point is not substituting transformation for aggregation of preferences. The point is that transformation is inevitable. What makes the difference normatively is what kind of transformation political preferences undergo in the political process. There is an underlying concern here that can best be expressed in terms of a theory of freedom. The concern for how and under what conditions our political preferences are formed is a concern for autonomy. I see the issue of autonomous preference formation as a third dimension of freedom within a broader theory of freedom. This theory includes one more dimension of freedom than the three already mentioned, one that has not gained the attention it deserves; namely, freedom as a form of status.

Thus, we arrive at four main dimensions of freedom. In addition to (1) political freedom and (2) individual freedom, we have (3) autonomous preference formation and (4) freedom as status. None of these dimensions of freedom are exclusive to deliberative democratic theory, but I maintain that the latter has a unique ability to incorporate all four dimensions and that it can supply new and valuable interpretations of them. ${ }^{4}$

Earlier theories of deliberative democracy have not paid sufficient attention to the multiple dimensions of freedom. I highlight the importance of the issue of autonomous preference formation, while showing some pitfalls in focusing exclusively on this dimension of freedom. For this purpose, a critical analysis of the works of Jon Elster and Cass Sunstein is most instructive. Elster and Sunstein give the issue of autonomous preference formation center stage. ${ }^{5}$ They both explicitly aim to clarify conceptions of autonomy that can be coupled with the theory of deliberative democracy. Not all proponents of deliberative democracy follow either of the two directly, but I believe that the two represent exemplary articulations of the idea that democratic theory should be concerned not merely with aggregation but also with transformation of preferences that underlies most versions of deliberative democracy. ${ }^{6}$ The idea of endogenous preference formation, which is at the center of both Elster's and Sunstein's theories, is the key to that contrast. I argue that the connection between this idea and a broader theory of freedom needs to be clarified.

By analyzing Elster's and Sunstein's theories from the perspective of a theory including multiple dimensions of freedom, we can see that what they regard as necessary in order that preferences are not adaptive runs counter to some other ideas of what freedom requires. I share with Elster and Sunstein the basic idea that autonomy cannot be identical with want satisfaction because the wants might not themselves be autonomously formed. But neither of their theories gives us an understanding of autonomous preferences that can be combined with a commitment to the other dimensions of freedom. 
I concentrate on two other dimensions of freedom that are crucial to a full understanding of autonomous preference formation, particularly if we want to avoid charges of paternalism. The first dimension is the status conception of freedom that refers to the treatment of each other as capable of giving and responding to reasons in the process of public deliberation. The other dimension is the freedom of being subject only to laws that are the product of deliberative processes in which one is able to take part.

It has been overlooked that the way of articulating the issue of autonomous preference formation, of which Elster's and Sunstein's theories are exemplary, is difficult if not impossible to connect to the other dimensions of freedom that deliberative democrats should care about. The common problem with their approaches is that they see nonautonomous preference formation as an individual problem that some citizens have. In Elster's work, this leads to a too narrow focus on individual-psychological factors and to a neglect of the political and intersubjective dimensions of freedom, while it in Sunstein' work leads to a justification of state paternalism. In contrast to these approaches, I see nonautonomous preference formation as a problem for all citizens. The problem is the communication structure of society in which each and every one forms her political preferences. We should see public deliberation as a collective learning process in which no one can form her political opinions freely unless everyone does so. If we do this, he very possibility that some paternalistically can make others autonomous from without or by bypassing their critical faculties is shown to be nonexistent.

\section{NONCONSCIOUS PREFERENCE FORMATION: ELSTER'S SOUR GRAPES}

Elster's discussion of sour grapes, or adaptive preferences, relates to discussions of deliberative democracy as a critique of the mere aggregation of preferences as the best means to determine just outcomes. The question he poses is as follows:

[W] hy should individual want satisfaction be the criterion of justice and social choice when individual wants themselves may be shaped by a process that preempts the choice? And in particular, why should the choice between feasible options only take account of individual preferences if people tend to adjust their aspirations to their possibilities? ${ }^{7}$

In other words, why care about people's choices, if they have not formed their choices freely? Thus, Elster is clearly concerned with a problem concerning 
freedom. But it is not clear exactly what the problem for freedom is and whether there is any way around it.

"Adaptive preference formation is the adjustment of wants to the possibilities - not the deliberate adaptation favoured by character planners, but a causal process occurring non-consciously." ${ }^{18}$ Elster contrasts adaptive preference formation to character planning, as advocated by Stoic, Buddhist, or Spinozistic philosophies, ${ }^{9}$ and makes a "distinction between the causally induced and the intentionally engineered adaptation of preferences to possibilities." ${ }^{, 10}$ The latter part of the distinction refers to character planning and is seen by Elster as "much more compatible with autonomy than are either manipulated preferences or adaptive ones," inevitable through choice than by non-conscious resignation." 12

Is Elster right that consciousness and choice always are better and more compatible with autonomy than nonconscious adaptation? They might be so only under certain conditions. Most seriously, the idea of character planning might be a dead end that can stand in the way of emancipation. One problem with the idea of character planning is that we might not be satisfied with calling a person's preferences autonomous merely because they are consciously and reflexively formed. Like the contemporary Spinozistic theory of free will advanced by Harry Frankfurt, Elster sees autonomy as characterized by meta-preferences shaping first-order preferences. ${ }^{13}$ Meta-preferences are reflexive preferences about which first-order preferences should be one's effective will. Now, it is possible that something a person does from a metapreference is something that she was made to do by "irrelevant causal influences"; that is, influences that detract from autonomy and rationality. ${ }^{14}$ The power structures, the social norms, and even the educational system of contemporary society might be such that they make some people reflexively endorse subordinate positions and unfair treatment. So even if a person consciously endorses her preferences it does not necessarily mean that the endorsement is arrived at freely. The mere form of reflexivity does not contribute to freedom if there is no qualitative difference between first-order preferences and reflexive ones. ${ }^{15}$ Elster admits that meta-preferences might be adaptive, ${ }^{16}$ but then it is not clear why their existence would contribute to freedom at all.

According to Elster, an advantage with character planning is that it makes it possible to "shape one's wants to coincide exactly with . . . one's possibilities, whereas adaptive preferences do not lend themselves to such finetuning." ${ }^{17}$ Adaptive preferences tend to overshoot; that is, to adapt more than necessary, to make one want even less than is actually possible. It is important to emphasize three points here. First, character planning or adjusting one's wants to the possibilities only matters if one has knowledge of the possibili- 
ties. It is true that nonconscious preference formation excludes the possibility of fine-tuning, but being conscious does not change anything unless one has adequate knowledge of the external world.

Second, character planning is aimed at changing the self, not at changing the external world. As such it is concerned with inner freedom rather than political freedom. ${ }^{18}$ Elster holds that character planning "could never detract from" autonomy. ${ }^{19}$ But could it not? The Stoic view where freedom is a matter of controlling one's self by either adapting to the world or making oneself as independent of it as possible might, I think, detract from the possibility of forming autonomous preferences about the world. The Stoic view of the relationship between the self and external world is characterized by resignation. Epictetus's The Handbook, for example, is in the main a prescription of how to avoid disappointments. ${ }^{20}$ But anyone who has been politically active knows that politics is filled with failed hopes. The Stoics concentrate on the control of one's own character because that is something that seems to be "up to us," as opposed to the organization of the external world, which is seen as "not up to us." ${ }^{21}$ In a sense they are right, political action does, because it involves a multiplicity of actors, set in motion chains of cause and effect, the results of which the actors cannot entirely control. The Stoic ideal of mastership and control of self can be achieved only by turning away from the unpredictability of acting with others and turning inward. In this way it expounds a view of freedom that is essentially nonpolitical. ${ }^{22}$ Of course, it matters how one has come to hold one's view that it is better to change the self than the world. Under certain conditions I could imagine that this would be the best alternative; sometimes there really are no possibilities for changing the world to fit one's preferences, and adjusting to this fact might then be the most reasonable thing to do. My point is that sometimes character planning can detract from autonomy, namely, when it is not even considered whether the world could be different and is accepted uncritically. The character planner tends to see the world as independent of herself and hence is foreign to the possibilities of collective, transformative action. Someone who has accepted the status quo as inevitable and shaped her preferences accordingly, even if she has done so reflectively, will not be open for a change of circumstances that would give her greater autonomy. She has already endorsed her preference and her circumstances. The danger is if she thinks she is free, because then she has excluded the possibility that she could become freer or that there are other dimensions of freedom. A preference that is consciously adopted, combined with a belief that one is free, might stand more in the way of freedom than an adaptive preference combined with no illusions about being free. 
Third, a character planner has accommodationist preferences. ${ }^{23}$ An accommodationist preference is distinguished from an adaptive one by being consciously formed. Accommodation is of course the only possibility for the one seeking harmony between herself and the world and only seeks to change herself. The problem here concerns not how the preference has been adaptedconsciously or nonconsciously-but what it has been accommodated to. It seems that accommodation to the circumstances only becomes a problem for freedom if there is in some sense something unfree about the way in which one came to live under those circumstances.

My discussion of Elster has shown some problems regarding the issue of adaptive preference formation as merely an inner issue. This perspective runs the danger of leading to the idea that freedom can be attained by individually becoming conscious of one's adaptive preferences and reflectively finetuning them to coincide exactly with the possibilities. This is a subjectivist view of freedom that is antithetical to any idea of political freedom and also to the idea that external circumstances matter for freedom. I do not deny that consciousness of one's preference formation matters for freedom, but the way in which Elster has formulated the issue leads to a dead end where it cannot be connected to the political and external dimensions of freedom, and hence cannot be the basis for social criticism. And there is not any room here for intersubjective processes of learning or for freedom as something that can be attained in deliberation with others. In particular, there is a pitfall in the idea of freedom as character planning insofar as people who reflexively endorse their preferences and their adaptation to their possibilities think that is sufficient for freedom. This view preempts any reflection regarding whether there might be more that is required for being free. And it ignores that the mere form of reflexivity does not exclude the possibility that citizens have merely adopted - uncritically or even nonconsciously - their metapreferences from the society in which they live. To be free we must also acquire our reflexive attitudes freely.

The idea of public deliberation gives us a better idea of what autonomy requires. Participating in deliberation is, ideally, a way of going beyond the mere fact of having meta-preferences and of scrutinizing one's possibilities on the basis of the available information. Deliberation triggers self-reflection not only regarding one's first-order preferences but also regarding one's reflexive preferences. It does so because one must be willing to defend one's opinions and give reasons for them to others and because one must be willing to listen to the reasons others have for their views. The deliberative process also imparts information about the world because this inevitably will be part of the arguments given for different points of view. By participating in com- 
mon deliberation, our reflexive judgments become products of intersubjective learning. Common deliberation, thus, achieves the sought-for qualitative difference between acting on first-order desires and acting on reflexive judgment, because the latter alone is based on reasons and knowledge gained intersubjectively. The difference from Elster and Frankfurt is that it is not the reflexivity as such that matters. Rather, what makes a preference autonomous is that it has survived a certain process. And this process is not merely an internal and subjective one; it is one in which you can check your preferences against the arguments of others. My preference is autonomous if I still find reasons to hold it after I have heard the relevant arguments and considered the relevant information. We thus get an intersubjectivity and a rationality component absent in Elster and Frankfurt.

It might be objected that I here run into the problem of infinite regress; the problem of how to avoid ascending to higher and higher levels to reach the autonomous self without cutting the sequence off arbitrarily. In one way this is true. Every result of deliberation is only temporary. I might hear new arguments and learn about new information that make me change my mind. Thus I learn that I did not have sufficient reason to hold my former view and hence that it was not fully autonomous. But I do not think this is a problem. In fact, it might be seen as what autonomy is all about: to be continually open to learning, to revise one's views in the light of new arguments. This means that we cannot define autonomy as a final state, as in Frankfurt's harmony between different levels of desires. The problem with Frankfurt's view might exactly be to see autonomy as a state of affairs, for seeing it thus inevitably leads to the infinite regress problem. Rather, we should see autonomy as a process. Autonomy, then, is to live under conditions in which one can engage with others in deliberative practices that enable one continually to modify one's preferences and opinions in light of arguments. ${ }^{24}$

\section{PREFERENCES AND PATERNALISM: SUNSTEIN}

Like Elster, Sunstein is concerned with endogenous preference formation. His intervention arises from a concern to defend government regulation and social redistribution. It is also part of an argument for deliberative democracy, but this aim is not well integrated with the first aim, or so I argue. It is a weakness of Sunstein's account that it is unclear what the perspective he is speaking from is and also who the agent of change should be. Both of these questions need to be answered by a theory with critical-transformative intent. 
Sunstein argues that democratic governments should not always respect private preferences, because these preferences are "adaptive to a wide range of factors-including the context in which the preference is expressed, the existing legal rules, past consumption choices, and culture in general." 25 This leads him to reject the notion of autonomy as preference satisfaction.

The notion of autonomy should refer instead to decisions reached with a full and vivid awareness of available opportunities, with reference to all relevant information, and without illegitimate or excessive constraints on the process of preference formation. When these conditions are not met, decisions should be described as unfree or non-autonomous; for this reason it is most difficult to identify autonomy with preference satisfaction. ${ }^{26}$

Given these commitments, Sunstein concludes, "A democratic government should sometimes take private preferences as an object of regulation and control . . . and precisely in the interest of welfare and autonomy."27

With this one-dimensional take on freedom and autonomy, Sunstein opens himself up to the charge of paternalism, for who is to decide when a preference is free, if not a paternalistic state? Sunstein's requirements for autonomy are so demanding that it is clear that no one will ever be autonomous, and hence the state always is justified in overruling our-the citizens'preferences. There are two problems here. First, there is a danger in seeing autonomy as a matter of either-or instead of as a matter of degree. It means that someone who is not fully autonomous is not autonomous at all, and hence you cannot violate her autonomy. Preferences that are not fully autonomous lose all worth.

Second, even if it is true that our preferences are not autonomous, it does not mean that they can be made so by the action of an external authority, such as Sunstein describes the state. According to Sunstein, "Respect for preferences that have resulted from unjust background conditions and that will lead to human deprivation or misery hardly appears the proper course for a liberal democracy." ${ }^{28}$ Thus, he goes directly from the problem of adaptive preference formation to a justification of state intervention. But this is too quick. It is one thing to say that adaptive preference formation is damaging to freedom and quite another to say that adaptive preferences should not be respected. We might try to solve the problem of adaptive preference formation while simultaneously respecting the preferences people actually have. This requires that we bring in the process of public deliberation. In deliberation, preferences must be respected, though we might seek to change each other's preferences through argument.

Sunstein says, "Social outcomes should not be based on existing preferences." ${ }^{29}$ But that is an unfortunate way to put what deliberative democracy is 
about. Political decisions should be based on existing preferences; political freedom requires that. The issue deliberative democrats should raise is how existing preferences have been shaped. And the perspective we should take is as critics in the public sphere who attempt to provoke reflection and contribute to processes of common deliberation..$^{30}$ As critical theorists, we can analyze how certain conditions and processes are detrimental to the free formation of preferences. But we should never from an external perspective take some preferences as not worthy of respect, and we should not see the state as an instrument to changing these preferences from without. That would violate both the negative and the political freedom of citizens. The normative commitment to multiple dimensions of freedom entails that we only try to change others' preferences by attempting to persuade them or make them reflect on their own situation and opinions. We cannot implement new conditions before we have convinced each other of their justifiability.

Sunstein does in fact consider the ideas of deliberation and political freedom, but he separates them from the issue of preferences. According to Sunstein, citizens should not decide "what they 'want,' but instead who they are, what their values are, and what those values require." ${ }^{11}$ Hereby he excludes the possibility of changing one's preferences about what one wants in the process of deliberation and makes it the concern solely of the output side of the state. Sunstein makes a too sharp distinction between wants and values. Even if we in politics cannot be concerned with our own interests and wants alone, it does not mean we cannot be concerned with them also. Political decisions should not transcend what we want individually but include it. Sunstein seems to want some preferences to be excluded before the process of deliberation gets started. I, in contrast, argue that it must be in the process of deliberation that it is decided what are and what are not "relevant preferences." People should be allowed to bring their private desires and interests to the process of deliberation; whether they should be satisfied must depend on whether there are good arguments for their satisfaction. And whether the preferences are autonomous must depend on whether people still hold them after they have seen them in light of the reasons given and the information imparted by public deliberation.

Sunstein makes the interesting observation that there often is a difference between people's wants as consumers in the market and their political val ues. ${ }^{32}$ This is a very important point to raise against those who say, "Hey, see people really don't want that" (those opera houses, speed limits, or whatever) and then point to their private consumption choices as proof. Sunstein is right to point out that the same people might have social aspirations and collective judgments that go against their private behavior. But he is not precise enough 
in relating this to the public process of deliberation and to the idea of selflegislation. The problem with his perspective is that he, exactly as those he criticizes, speaks on others' behalf. Sunstein's response to the objector to regulation is, "Yes, that is what they really want—as citizens." But it is exactly such an observer's perspective that public deliberation and respect for the multiple dimensions of freedom of citizens demand that we abandon. A basic normative commitment of deliberative democracy should be that everyone must speak for herself. It is crucial to emphasize that it is in public deliberation that we form our legitimate collective judgments and justify laws that might overrule our private desires. And, hence, it is only as participants in public deliberation that we can know what each other's political values are. This cannot be determined by observing theorists or judges, and not by opinion polls either. Consequently, there would be no question of the state's not respecting people's preferences and attempting to control them. It would be citizens themselves who formulate what their collective aspirations are and how they should relate to their own private desires.

The objections I have raised against Sunstein have their roots in a tension between a substantial commitment to state regulation and an argument for solving political problems through processes of public deliberation. Sunstein represents the tendency to weigh substantial commitments higher than respect for the democratic genesis of law through public deliberation. Deliberative democracy, however, should not only be concerned with the effects of the output of the state but also focus on the input. It makes a difference whether we see adaptive preference formation as an issue that should be solved by a state that takes an objective attitude (in P. F. Strawson's sense) ) $^{33}$ toward its citizens or whether we see it as an issue to be dealt with in public deliberation generating legitimate law. In the democratic genesis of law, we have to show respect for each other's preferences, even if they are the result of adaptation to unjust background conditions, not the least because we never will arrive at the situation of perfect justice and full autonomy. Instead of seeing the possibility of adaptive preferences as a direct justification for not respecting preferences, the thematization of the issue should be seen as a contribution to public deliberation. As critics in the public sphere, theorists of deliberative democracy should provoke deliberation about possible adaptive preferences, but they do not have the final word on the issue. They "are successful not in so far as they bring agents to particular true insights, but rather in so far as they initiate processes of self-reflection, the outcome of which agents determine for themselves." ${ }^{34}$

Now, Sunstein might object that he is not arguing for imposing anything on anybody. The social justice measures he proposes should, of course, be 
subject to debate and democratic voting. But this response misses the point. My argument is primarily directed at a too simplistic account of autonomy. Sunstein might say that he wants to combine this with a theory of deliberation and political freedom; my point is that he has not done so. But the argument also has institutional implications. Sunstein's account of autonomy will be less critical of forms of policy making that are isolated from popular participation and common deliberation than a theory that wants to combine the concern for autonomous preference formation with a concern for political freedom and the respect for each and every one as an authority on matters of common concern. ${ }^{35}$

In a couple of recent articles, Sunstein has made an argument in favor of what he and his coauthor Richard Thaler call "libertarian paternalism." Like the work discussed previously, this argument relies heavily on the premise of endogenous preference formation. The argument differs from Sunstein's argument concerning deliberative democracy by not being concerned with the effects of preference formation on the political process but by being concerned with welfare alone. ${ }^{36} \mathrm{But}$ it is instructive to see again what the empirical data that show that preferences often lack rationality and autonomy are believed to justify.

Libertarian paternalism is "an approach that preserves freedom of choice but that encourages both private and public institutions to steer people in directions that will promote their own welfare." ${ }^{37}$ Sunstein and Thaler's argument is based on two main premises: first, there are no viable alternatives to paternalism; second, paternalism does not always involve coercion. To illustrate the argument that there are no viable alternatives to paternalism, they give the following example:

Consider the problem facing the director of a company cafeteria who discovers that the order in which food is arranged influences the choices people make. To simplify, consider three alternative strategies: (1) she could make choices that she thinks would make the customers best off; (2) she could make choices at random; or (3) she could maliciously choose those items that she thinks would make the customers as obese as possible. Option 1 appears to be paternalistic, which it is, but would anyone advocate option 2 or $3 ?^{38}$

That the arrangement of the food influences the choices the customers make is an example of a number of ways in which behavioral economics and cognitive psychology research have shown that context shapes choice..$^{39} \mathrm{I}$ do not have a quarrel with this research but with what is done with it. Paternalism is inevitable, according to Sunstein and Thaler, because (1) the director has to make a choice about the arrangement of the food and (2) options 2 and 3 are 
not viable. It is undeniable that a choice has to be made (though it is less clear why it is the director who has to make it and why she knows better). But is it really true that option 2 is such a far-fetched option? Would it not be preferable in terms of freedom that the food be arranged randomly than that the director places the food in an order that makes the customers buy what she believes is best for them? Sunstein and Thaler propose that institutional planners ("anyone who must design plans for others, from human resource directors, to bureaucrats, to kings" $)^{40}$ study what behavioral economics and cognitive psychology can tell them about how people choose as a result of different institutional designs, default options, starting points, and so on, and on this basis steer people in a direction that will promote the latter's welfare. Then, to meet the concerns of the libertarian, they note that this form of paternalism is not coercive because it leaves people free to choose. The cafeteria director puts the unhealthy food in the back but does not make it unavailable; the employer makes her preferred pension savings plan the default option but makes it possible for the employees to opt out. But only a very crude notion of coercion would see this as coercion free. Coercion is a matter not merely of making options unavailable but also of raising the costs of certain options. What we witness is an argument for making people feel free by giving them the choice between a number of options while the institutional planners design the context so they achieve the desired outcome. The main objection to this way of thinking is the objectivating attitude it takes toward the subjects. The customers in the cafeteria and the employees choosing pension plans are treated as not being responsive to reasons but as mere objects that react in calculable and predictable ways to default rules, framing effects, starting points, and so on. ${ }^{41}$ If this is true, then there is more respect in randomness.

This discussion gives us even more reason to emphasize the political dimension of freedom. In cases where some decisions need to be made by "planners," the notion of negative freedom does not help us very much, and the decision cannot be made in anticipation of what choices people would make if the choices people make depend on the options they have: there would be no clear preferences to track. ${ }^{42}$ The fact that institutional rules affect the choices made gives us a good reason to make these institutional rules the object of reflection and collective decision making. So does the fact that steering choices, even if less oppressive than making certain choices unavailable, hardly can be seen as noncoercive. This does not mean that all areas of life should be democratized and no tasks could be delegated; for example, to bureaucratic agencies. But it does mean that the only way in which we can 
avoid paternalism is by making institutional rules subject to democratic legitimation.

\section{PATERNALISM}

It is a classical problem that in attempting to remove one form of oppression we impose another. Sunstein fails on this count because in his argument for state intervention for the sake of the autonomy of the subjects, he accepts paternalism. I have made this criticism from the perspective of an understanding of deliberative democracy as committed to multiple dimensions of freedom. To elaborate this perspective and show why it must be critical of paternalism, I spell out what exactly paternalism is, when it is at play, and why it is objectionable. ${ }^{43}$

Gerald Dworkin helpfully defines an act as paternalistic if it "constitutes an attempt to substitute one person's judgment for another's, to promote the latter's benefit." ${ }^{44}$ Any form of paternalism involves a person or a group of persons believing that she or it knows better what is in the best interest of another or others and attempts to impose her or its view on others. It is a case of legal paternalism when the judgment of the first party is backed by law, which in the last instance means that it is backed by force. A political system is paternalistic if it gives some the authority to judge on others' behalf what they believe promotes the latter's benefit.

Acting paternalistically entails that the subject does not know what is in her interest or what is good for her. But there is an ambiguity in saying that the subject does not know what is in her interest or what is good for her. It could mean that the person is mistaken about what her interests are or about what best serves her interests; that is, she can be seen as mistaken about either her ends or her means, or both. Regarding ends, note that the subject of a paternalistic act does not necessarily object because she does not share the end or good promoted but because she does not see it as the highest good. ${ }^{45}$ Thus a smoker who is against paternalistic smoking regulations might agree that health is a good, but she does not agree that it is the highest good. She might think it is a higher good to live well than to live for a long time. The judgment that the paternalist wants to substitute for that of the subject is, thus, a composite not only of what is good but also of what is best and of how best to achieve this end. This leads to three different forms of justification for paternalistic legislation: (1) people do not know what is good for themselves, (2) people do not know what is best for themselves (they do not have the right 
priorities), and (3) people do not know how to achieve what is good for themselves.

These forms leave out another candidate for justifications of paternalism; namely, weakness of will. If we accept that it is possible for a person to know what is good for herself, to have the right priorities, and to know how to achieve her ends and nevertheless fail to act accordingly, then there seems to be a prima facie justification for intervention. Among proponents of deliberative democracy, Amy Gutmann and Dennis Thompson, for example, see protecting against weakness of will as an act of paternalism and as being justified. ${ }^{46}$ But I do not think it is a case of paternalism at all. When another person or the law helps me do what I judge it best to do, or refrain from doing what I judge it detrimental to do, it is reinforcing my own judgment rather than putting another's judgment in its place. So according to the definition I have appropriated from Dworkin, acts that adjust for weakness of will are not paternalistic - which is not to say that they are always justified.

The focus on judgment in this definition is important. If we instead defined a paternalist act as one that goes contrary to the subject's operative preference, ${ }^{47}$ acts and laws adjusting for weakness of will would be paternalistic. But I think it is important to be able to distinguish between acts or laws that go against the subject's own judgment and those that reinforce her judgment against her weakness of will or some (ephemeral) operative preference. We see an important difference between the two in the ways in which they address their subjects. In the case of paternalistic acts, the subject is treated as incapable of judgment; in the second case she is seen as incapable of following through on her own judgments. But the most important difference is that the latter type can be self-imposed, while paternalistic acts cannot. Gutmann and Thompson's idea of "self-imposed paternalism" seems to me an oxymoron. ${ }^{48}$ Paternalism implies that someone else thinks she knows better than I do what is good for me and attempts to impose it on me, against my own judgment, for my own good. Self-imposition requires that I knew what was good for me, but that is exactly what the paternalist denies. But it is possible for me to impose on myself or ask others to impose on me constraints that help me overcome my weakness of will. Of course, legislation aimed at adjusting for weakness of will might, when accepted by a majority only, follow the judgment of some, while being paternalistic toward others. But then we are back to the case of some judging on behalf of others what are in the latter's best interest. And it is for this reason-that is sets the judgment of some over the judgment of others-that the legislation should be seen as paternalistic, and not because it sets judgment over operative preference. To be sure, the practical need for decision making according to the majority principle leads to fur- 
ther difficulties, because the deciding self is not coterminous with the affected self. ${ }^{49}$

\section{Can Deliberation Be Paternalistic?}

Procedure and Substance

The idea of deliberative democracy as committed to multiple dimensions of freedom entails, in contrast to the position Sunstein is representative of, that citizens' preferences must be respected and changed only as part of a process of public deliberation. I now elaborate and defend this position more fully in light of what I have said about the concept of paternalism. I do so by way of a response to Dworkin's claim that "it is not as if rational argument cannot be paternalistic while brute force must be. Some people may want to make their decisions impulsively, without rational deliberation; insisting that they hear rational argument (for their own good) is paternalism." ${ }^{50}$

Let us consider in what sense, if at all, rational argument might be considered a case of having one person's judgment substituted for another's, for the sake of the latter. First we must distinguish between imposing a substantial judgment on another and imposing (a judgment about) which decisionprocedure to follow. Dworkin seems to be concerned with the latter, but I begin by explaining why deliberation cannot be seen as a matter of imposing substantial judgments on others, and then I return to the issue of procedure.

My argument for public deliberation as connected to a theory of multiple dimensions of freedom does rely on the idea that people do not always know what is in their own best interest. Public deliberation should aim not only at coordinating action and determining collective goals but also at gaining greater insights into what is in our best interest individually and collectively. ${ }^{51}$ This description can lead some to suppose that deliberation is inherently paternalistic. But it is not paternalistic to point out that people might be mistaken about their own interests; it only becomes so if one thinks one knows better and attempts to substitute one's own judgment for another's. Deliberation does not work by imposing one person's judgment on others. It should rather be thought of as a joint activity of mutual learning. As I see it, one of the basic premises of deliberative democracy is that no one has privileged access to and uncriticizable beliefs about what the true interests of anyone are. In deliberation, it is true, there is a substitution of one judgment for another, but it is not of mine for yours, rather of what results from deliberation for both of them.

It could be objected that usually a person goes into an argument to substitute her own judgment for her listener's. To be sure, this can be the motivation 
for entering an argument, but this in itself clearly does not constitute a process of deliberation. The process of deliberation cannot be reduced to the motivations of those who enter it. While the reason for entering argument can be paternalistic, there is something about the process of argumentation that makes it defy being so. This is because the addressee of an argument will be able to accept or reject the argument in light of her own judgment, if nothing but argument is involved. If the initiator of the argument is able to prevent the addressee from considering the argument on its merits, it will be not by means of argument but rather by means of something external to it such as superior power or manipulation. ${ }^{52}$ In that case, what makes the act paternalistic is not the argument but the first person's ability to avoid a real argument from taking place, using forces external to argument itself. Thus, as speech acts, arguments do not fit the definition of paternalistic acts. That is also the case because they are directed at a person's conscious and reflective capacities and hence can be either accepted or rejected by the recipient on the basis of her own judgment. This is why I do not think arguments can be said to be irrelevant causal influences in the sense that they limit our freedom. Irrelevant causal influences can be characterized by their bypassing our reflective capacities. ${ }^{53}$ It makes a difference whether, on one side, another's judgment has been substituted for mine without my knowing it (as in the case of manipulation) or by means of overt force, or, on the other side, I have come to rationally accept this judgment as my own.

The preceding arguments, however, require that people deliberate in the first place. They apply only to persons who have already accepted participating in deliberation. So let us return to Dworkin's point that "insisting that [impulsive people] hear rational argument (for their own good) is paternalism." The situation here is not one of the substitution of another's substantive judgment for one's own but one of the substitution of another's preferred decision-procedure for one's own. That is, it is not a case of $A$ insisting that $B$ do $x$ rather than $y$ for her own sake, but of $A$ insisting that $B$ follow a certain procedure before she decides whether to do $x$ or $y$ for her own sake. And it is clearly the insisting that Dworkin calls paternalistic, not the rational argument. But what is meant by "insisting"? Let us consider two examples regarding legal paternalism, one that relates to the output side of the state and one that relates to the democratic genesis of law.

Consider a law that requires a woman who wants to have an abortion to go to counseling before she gains the right to have it. ${ }^{54}$ Suppose this law is made for the sake of the autonomy of the woman in the sense that her choice will only reflect what she really wants if it is made after having considered the pros and cons of the case. ${ }^{55}$ This is a case of insisting that someone hear ratio- 
nal arguments before she makes up her mind. Note that the complaint against such a law would most likely not be against rational arguments as such but be against being forced to listen to them. The complaint would be against the legal rule not the argument. If one were against arguments as such, one would have to be in favor of prohibiting from the public sphere arguments that make pregnant women reflect on whether to have an abortion. A law forcing people to listen to arguments for their own good before they make personal choices would be paternalistic, I contend, but a law that allows arguments in the public sphere meant to make people reflect on their choices is not. The difference is that in the first case people are forced to do something independently of their own judgment, while in the latter case they will only listen to the arguments if they so choose. I draw this distinction not merely to affirm the importance of free speech but to argue that an increase in public deliberation should not be seen as a threat to freedom. As long as citizens have the right not to participate in public deliberation, the negative dimension of freedom has been respected. The problem with obligatory abortion counseling is the lack of a right to say no; it is paternalistic when it is justified with reference to one's own good.

The second example, relevant to the democratic genesis of law, is the idea that people would be given the right to vote only if they took part in public deliberation. Suppose that such a law was justified with reference to the fact that many individuals vote contrary to their own best interests. Justified in this way, the law is paternalistic vis-à-vis those who would prefer to make up their mind about how to vote without participating in public deliberation. But again the objection would be not that arguments are paternalistic per se but that being forced to listen to them is. The problem for deliberative democracy in this connection is not that deliberation as such is paternalistic but that it is impotent by itself in face of those who do not want to listen. To increase participation in deliberation, one might have to use nondeliberative means such as rewards or punishments. Deliberative democracy, as I see it, does not by its very idea outlaw using the law to promote participation in deliberation. But I do not think the justification for such laws should be a paternalistic one. Rather than being justified by reference to the good of the person herself, it would have to be justified by reference to the fact that when we act politically we make choices that not only affect ourselves but affect everybody. ${ }^{56}$ So any argument for institutions and laws that make people take part in deliberation before they vote- or encourage them to do so—-should not be justified with reference to their own good but be justified with reference to the idea that they are not merely exercising power over themselves, rather also over others. 
In these two examples the negative dimension of freedom, the freedom from coercive interference, also shows its importance. But my argument shows that we should be careful not to confuse this dimension of freedom with the idea that public deliberation in itself encroaches on freedom. Or at least we should be able to distinguish coercive interference from the unavoidable and unobjectionable "interference" posed by the existence in one's society of arguments that contradict one's own convictions.

\section{SELF-LEGISLATION AND FREEDOM AS STATUS}

There are some arguments against paternalism that are inherent to the deliberative democratic perspective. These arguments become clearer when we explicate the dimensions of freedom this perspective must be normatively committed to. What distinguishes the paternalist and the deliberative democratic point of view is not that one holds that people do not know what is good for themselves, while the other thinks they do. The difference is rather that the paternalist believes she knows what is good for others and feels herself justified in imposing her judgment on others, while the deliberative democrat believes that what is right must be justified and accepted in deliberation. A basic assumption underlying deliberative democracy, as I see it, is that no one has privileged access to truth or to the true interests of others. The only way to arrive at judgments that have the presumption of being right on their side is through public processes of deliberation in which everyone is free and able to participate. ${ }^{57}$

If subjects of paternalistic legislation have not been convinced of the justifiability of the legislation, this legislation cannot be said to enhance their autonomy ${ }^{58}$ - though it might increase their welfare, an issue I leave aside. It is on this issue I differ with Sunstein. From the standpoint of deliberative democracy as normatively committed to multiple dimensions of freedom, we can see why it is unsatisfactory to limit freedom to the idea that preferences be formed consciously and under just circumstances. There are two dimensions of freedom, both inherent to deliberative democracy, that Elster and Sunstein neglect: freedom as self-legislation and freedom as status. Both freedom as self-legislation and freedom as status are related to the freedom of the ancients, but in the deliberative democratic reinterpretation of the latter it is seen as involving two distinct dimensions. ${ }^{59}$

What is objectionable about paternalism from the deliberative democratic point of view is that the paternalist does not want to go into an argument about her own view but wants to impose it on the subject from without. This goes 
against the very idea of deliberation. Deliberation is about convincing, and when a speaker is successful in convincing the hearer about her proposal, the implementation of this proposal will be a case not of imposing the judgment of the former on the latter but of the two having come to share judgment. This leads us to the idea of self-legislation. Paternalism is a matter of some attempting to judge and legislate on behalf of others for the latter's own good, while self-legislation is a matter of giving a law to oneself on the basis of one's own best judgment. On this understanding, laws given to oneself can never be paternalistic, since they are reinforcing rather than going against one's own best judgment.

The paternalist's attitude not only goes against freedom as self-legislation but also goes against freedom as a form of status. Status can be seen as a dimension of freedom. ${ }^{60}$ Freedom as status "identifies freedom as a position occupied by a person within a particular political and social structure." ${ }^{\prime 61}$ Deliberative democracy implies a specific view of what it is to be a citizen and involves a particular understanding of freedom as status. The paternalist does not recognize the status we must give each other for common deliberation to succeed. In deliberation, we must respect the status of each other as free persons, in the sense of persons worth arguing with and as persons who can contribute and respond appropriately to reasons. Everyone must be given the status of an authority on matters taken up in public deliberation. ${ }^{62}$ This status is violated when others overrule our judgments and implement what they deem good for us, even if it is something they believe will increase our autonomy.

The argument for self-legislation will naturally be met by the majorityminority objection. We need to distinguish more clearly than I have done hitherto between "my judgment" and "our judgment." Without consensus, my judgment and the collective judgment that determines the decision do not necessarily coincide. Consensus is rarely, if ever, forthcoming regarding matters of legislation, the objection goes, and the majority who makes the decision will thus judge on behalf of the rest. It is undeniable that consensus rarely occurs in legislative politics, but it is true only up to a point that this means that the majority has to impose their judgment on the minority. If there has been an inclusive and free process of deliberation up to the point of decision making, then the freedom of even the minority has been respected in two ways.

First, the results of deliberation are also products of the contributions made by those who ended up in the minority. "Although the result does not conform to all points of view, it is the result of the confrontation between them." ${ }^{63}$ This process constitutes for everyone freedom as being a participant 
in self-legislation. I distinguish being a participant in self-legislation from being a self-legislator. The latter requires that you be in agreement with the final decision made, while being a participant in self-legislation is possible even if you disagree with the final result, as long as the final decision is also affected by your contribution and as long as it is seen as fallible and reversible and therefore subject to further debate by the demos as a whole. It is only when we see democracy as a deliberative democracy that we see this possibility; that is, when we see that opinion formation is as important as the counting of votes. It might be objected that this argument requires that the results of democratic decision making be different because of the contributions made by the outvoted minority and that this condition is not always fulfilled. But, if we look not at isolated instances of decision making but at the long-term effects of a more deliberative society, then the condition that all participants actually do affect the decisions is harder to refute. Decision making will be embedded in a different environment, which will affect the opinion and will formation of everyone and hence will lead to different results.

Second, under these conditions, even if you end up in the minority, your status is respected. The fact that the majority does not end up agreeing with you does not mean that they have not listened to your arguments and given theirs, and they have to respect it if you criticize their judgment and attempt to change the decision made.

Thus, the fact that decisions in the end have to be made following the majority principle does not mean that the argument for the antipaternalism of deliberative self-legislation fails. A decision reached after public deliberation is not merely a case of the judgment of the majority substituting for that of the minority but a case of judgments clashing and resulting in something new. And even if the outvoted minority must obey the decision made by the majority until they can win the majority, they are not required to accept the judgment behind the decision made as theirs. ${ }^{64}$

Note that these points concern procedures and not substance. It would be wrong to say that if the substance of what the majority decides is just and it is meant to promote the autonomy of the minority, then it is justified and does promote autonomy. To be free is a matter not just of living under just laws or under conditions that promote autonomous preference formation but of having been personally convinced of what is right and of giving the law to oneself on that basis. We cannot put in place new conditions before having attempted to convince each other of their justifiability without violating both freedom as status and freedom as being a participant in processes of selflegislation. These are the requirements of the deliberative procedure that exclude paternalism. 


\section{CONCLUSION}

The argument in this article is not meant as a rejection of any and all paternalistic legislation. Rather, the aim has been to disentangle deliberative democracy from paternalism; that is, to show that deliberative democracy is not a particularly or inherently paternalistic model of democracy-even if paternalistic legislation sometimes is agreed on as it is in any democracy. Deliberative democracy does not require paternalistically disregarding people's existing political preferences for the sake of autonomous preference formation. This can be seen from an analysis of what processes of public deliberation require and by explicating the different dimensions of freedom they imply.

If we do not see the issue of nonautonomous preferences in the broader context of a theory of deliberative democracy normatively committed to multiple dimensions of freedom, we too easily end up in the paradoxical situation of seeking to increase autonomy in ways that simultaneously undermine it. Sunstein ends up in this predicament because he wants to make people's preferences autonomous in a way that disrespects their freedom as reasonresponsive beings and undermines the freedom of being participants in selflegislation. Or we end up in a too narrow focus on the self at the cost of the political and external dimensions of freedom, as I have argued that there is a tendency to in Elster. The analysis of Elster and Sunstein also shows that onedimensional views of autonomy fail to give us standards in light of which social criticism can be made. Elster's idea of character-planning moves the focus away from the importance of social circumstances, while Sunstein fails to tell us the perspective from which criticism should be made and who the agent of change should be.

Juxtaposing the idea of a normative commitment to multiple dimensions of freedom to Elster and Sunstein matters particularly in terms of what we think the possibility of adaptive preferences can justify. My argument entails that the existence of adaptive preference formation cannot be used as a direct or unmediated justification for state intervention. If we begin to set up external standards for when people's preferences are autonomous, then we have betrayed the promise of deliberative democracy as a truly democratic model committed to multiple dimensions of freedom; a model where standards must be the product of processes that give each one of us the ability to learn and contribute and that treats each one of us as responsive to reasons rather than to authority and force. Critical theorists can raise the issue of adaptive preferences in the public sphere but not solve it. For preferences to be autonomously formed, citizens need to have formed them by their own lights and under conditions that they have been able to participate in the justification of. 
If there is a problem of adaptive preference formation in society, this is not an individual problem with an individual solution or a problem that some can solve for others through state action. Rather, it is a problem with the communication structure in which all of us form our preferences and something that can be solved only on the basis of intersubjective processes of deliberation.

The focus on multiple dimensions of freedom entails an argument for seeing deliberative democracy as situated between models of democracy that claim democracy requires that we hold that people are never wrong about their own interests (or even if they are, that there is nothing we can do about it, because it would violate their negative freedom) and paternalistic models that set up independent standards of what is good for people. It is possible to raise the issue of nonautonomous preferences without substituting one's own judgment for those of others. Public deliberation is a means of dealing with nonautonomous preferences without becoming paternalistic. It works through its participants' own critical faculties and is undermined by mechanisms that bypass these. Because of its procedural and dialogical character, deliberation cannot impose anything on anybody. The strength of deliberative democracy is exactly that it can challenge uncritically accepted forms of oppression without being paternalistic and setting up external standards of true and false interests. We only see the importance of this when we clarify the dimensions of freedom to which deliberative democracy must be normatively committed.

\section{NOTES}

1. On the point that critical theory is intrinsically linked to a theory of freedom, see Albrecht Wellmer, Critical Theory of Society, trans. J. Cumming (New York: Herder and Herder, 1971), 48f; and Raymond Geuss, The Idea of a Critical Theory: Habermas and the Frankfurt School (Cambridge: Cambridge University Press, 1981), 78. For the point that a critical theory must clarify its normative standards, see Seyla Benhabib, Situating the Self: Gender, Community and Postmodernism in Contemporary Ethics (New York: Routledge, 1992), 33; and James Bohman, Public Deliberation: Pluralism, Complexity, and Democracy (Cambridge, MA: MIT Press, 1996), 11.

2. The most ambitious attempt at such reconciliation is Jürgen Habermas, Between Facts and Norms, trans. William Rehg (Cambridge: Polity Press, 1996). It is also an aspiration for John Rawls; see Political Liberalism (New York: Columbia University Press, 1993), 4f; and for Joshua Cohen, who makes two quite different arguments for it in "Deliberation and Democratic Legitimacy" and in "Procedure and Substance in Deliberative Democracy," both in Deliberative Democracy: Essays on Reason and Politics, ed. James Bohman and William Rehg (Cambridge, MA: MIT Press, 1997), 67-92, 407-37.

3. In this article I focus on autonomous preference formation rather than justification. This does not mean that I think that the first can be seen independently of the latter. In deliberative 
democracy, as I see it, the value of autonomy is relevant only insofar as it affects the process of mutual justification of issues of common concern. Thus, while I here for the sake of simplicity focus on autonomous preferences independently of their justifiability, it is important to keep in mind that the two issues cannot be disentangled when we are concerned with democracy as a theory of what is right rather than a theory of the good life. As Rainer Forst notes, "Critical theory ... is a critique of existing 'relations of justification' as the presupposition for establishing and developing a justified basic structure of society." See "Justice, Reason, and Critique: Basic Concepts of Critical Theory," in The Handbook of Critical Theory, ed. David Rasmussen (Oxford: Blackwell, 1996), 138-62, at 158.

4. The argument in this article is only a part of this broader claim, which I defend more fully in "Deliberative Democracy and Conceptions of Freedom" (PhD diss., Columbia University, 2004).

5. Or actually I should say on nonautonomous preferences. There has been much more theorizing about the negative case of adaptive preferences than the positive case of autonomous preferences. Jon Elster, Sour Grapes: Studies in the Subversion of Rationality (Cambridge: Cambridge University Press, 1983), esp. chap. III; Cass Sunstein "Preferences and Politics," Philosophy and Public Affairs 20 (1991):3-34; and Cass Sunstein, The Partial Constitution (Cambridge, MA: Harvard University Press, 1993), chap. 6. Elster admits he "can offer no satisfactory definition of autonomy." See Sour Grapes, 21. Instead, he delineates autonomy negatively; ibid., 22. See also Jon Elster, "The Market and the Forum: Three Varieties of Political Theory," in Deliberative Democracy: Essays on Reason and Politics, 3-33, at 9.

6. See, for example, Joshua Cohen, "Democracy and Liberty," in Deliberative Democracy, ed. Jon Elster (Cambridge: Cambridge University Press, 1998), 185-231, at 185ff; and Iris Young, Inclusion and Democracy (Oxford: Oxford University Press, 2000), 18ff.

7. Elster, Sour Grapes, 109.

8. Ibid., 25.

9. Ibid., 110, 117.

10. Ibid., 110

11. Ibid., 128

12. Ibid., 118

13. Elster describes character planning as involving preferences being shaped by metapreferences; Sour Grapes, 117. This idea is very close to Harry Frankfurt's hierarchical theory of freedom; see Frankfurt, "Freedom of the Will and the Concept of a Person," in The Importance of What We Care About: Philosophical Essays (New York: Cambridge University Press, 1988), 1125. For a discussion of Frankfurt, see Christian F. Rostbøll, "Freedom as Satisfaction? A Critique of Frankfurt's Hierarchical Theory of Freedom," Sats: Nordic Journal of Philosophy 5, no. 1 (2004): 131-46.

14. Elster, Sour Grapes, 16; see also "The Market and the Forum," 9.

15. This point is similar to a common objection to Frankfurt's theory. We can ask with Gary Watson, "Can't one be a wanton, so to speak, with respect to one's second-order desires?" See Watson, "Free Agency," in Free Will, ed. Gary Watson (Oxford: Oxford University Press, 1982), 96-110, at 108 .

16. Elster, Sour Grapes, 21.

17. Ibid., 118

18. For a critique of Stoicism for beginning the decline of the idea of freedom as something pertaining to politics, see Hannah Arendt, "What Is Freedom?" in Between Past and Future: Eight Exercises in Political Thought (Harmondsworth: Penguin Books, 1993), 143-72, at 147f.

19. Elster, Sour Grapes, 138. 
20. "Do not seek to have events happen as you want them to, but instead want them to happen as they do happen, and your life will go well," as Epictetus succinctly formulates the Stoic view in The Handbook, trans. Nicholas White (Indianapolis: Hackett, 1983), c. 8, p. 13.

21. Epictetus begins The Handbook by emphasizing the premise, "Some things are up to us and some are not up to us," c. 1, p. 11. It seems that even though he uses the plural he really means "up to us individually" and not "up to us in common or together."

22. Cf. Hannah Arendt, "What Is Freedom?" 147, and The Human Condition (Chicago: University of Chicago Press, 1958), 222, 234, 244.

23. Joshua Cohen, "Deliberation and Democratic Legitimacy," 78.

24. As I argue later, these conditions must be justified in deliberation.

25. Sunstein, "Politics and Preferences," 5.

26. Ibid., 11, emphasis added. Similar definitions of autonomy are given in The Partial Constitution, 176, and Designing Democracy: What Constitutions Do (New York: Oxford University Press, 2001), 163.

27. Sunstein, "Politics and Preferences," 13. Similarly, The Partial Constitution, 178.

28. Sunstein, "Politics and Preferences," 10. Similarly, The Partial Constitution, 175.

29. Sunstein, The Partial Constitution, 163.

30. For a good discussion of social critics in the public sphere, see Bohman, Public Deliberation, chap. 5.

31. Sunstein, "Politics and Preferences," 13. Similarly, The Partial Constitution, 178.

32. Sunstein, The Partial Constitution, 179ff.

33. See Peter Strawson, "Freedom and Resentment," in Free Will, ed. Gary Watson (Oxford: Oxford University Press, 1982), 59-80.

34. James Bohman, "Habermas, Marxism and Social Theory: The Case for Pluralism in Critical Social Science," in Habermas: A Critical Reader, ed. Peter Dews (Oxford: Blackwell, 1999), 53-86, at 80.

35. What the exact institutional implications of the alternative accounts would be is a complicated issue that I cannot go into here. But it is important to stress that they do have institutional implications of the sort I mention in the text.

36. Cass R. Sunstein and Richard H. Thaler, "Libertarian Paternalism Is Not an Oxymoron," University of Chicago Law Review 70 (Fall 2003): 1159-202, at n22.

37. Ibid., 1201.

38. Richard H. Thaler and Cass R. Sunstein, "Libertarian Paternalism," American Economic Review 93 (May 2003): 175-79, at 175.

39. Generalizing from this research, Sunstein and Thaler's main empirical premise is that what people "choose is strongly influenced by details of the context in which they make their choices, for example default rules, framing effects (that is, the wording of possible options), and starting points"; "Libertarian Paternalism Is Not an Oxymoron," 1161.

40. Thaler and Sunstein, "Libertarian Paternalism," 178.

41. Sunstein and Thaler note "that respect for autonomy is adequately accommodated by the libertarian aspect of libertarian paternalism," that is, the availability of opt-out options; see "Libertarian Paternalism Is Not an Oxymoron," n22. But autonomy for libertarians is not merely a matter of existence of choice but also a matter of Kantian respect for others as ends; cf. Robert Nozick, Anarchy, State, and Utopia (New York: Basic Books, 1974), $30 \mathrm{f}$.

42. "What people choose often depends on the starting point, and hence the starting point cannot be selected by asking what people choose"; Thaler and Sunstein, "Libertarian Paternalism," 178.

43. Among deliberative democrats, Habermas has repeatedly warned against the dangers of paternalism, but to my knowledge he has never given a definition of the term. Habermas 
describes uncritical affirmation of the status quo and assuming a paternalistic role, as the two poles political philosophy should navigate between. “ 'Reasonable' versus 'True,' or the Morality of Worldviews," in The Inclusion of the Other: Studies in Political Theory (Cambridge, MA: MIT Press, 1998), 75-101, at 97. He also repeatedly warns against paternalism in Between Facts and Norms.

44. Gerald Dworkin, "Paternalism: Some Second Thoughts," in The Theory and Practice of Autonomy (Cambridge: Cambridge University Press, 1988), 121-29, at 123.

45. Cf. Gerald Dworkin, "Paternalism," Monist 56 (1972): 64-84, at $78 f$.

46. Ann Gutmann and Dennis Thompson, Democracy and Disagreement (Cambridge, MA: Belknap Press of Harvard University Press, 1996), 263.

47. For such a definition, see Donald VanDeVeer, Paternalistic Intervention: The Moral Bounds on Benevolence (Princeton, NJ: Princeton University Press, 1986), 22.

48. Gutmann and Thompson, Democracy and Disagreement, 264.

49. Or this is one way of seeing the problem, which I return to later.

50. Dworkin, "Paternalism: Some Second Thoughts," 123.

51. I think Jane Mansbridge is right in arguing that we need a full deliberative system "if citizens are, in any sense, to rule themselves." In a full deliberative system, "people come to understand better what they want and need, individually as well as collectively." See "Everyday Talk in the Deliberative System," in Deliberative Politics: Essays on Democracy and Disagreement, ed. Stephen Macedo (New York: Oxford University Press, 1999), 211-39, at 211.

52. This understanding of argument is indebted to Jürgen Habermas's theory of communicative action; see his The Theory of Communicative Action vol. I, trans. Thomas McCarthy (Cambridge: Polity Press, 1984), 8-42, 273-338. For an exposition, see Christian F. Rostbøll, Human Rights, Popular Sovereignty and Freedom (Copenhagen: Copenhagen Political Studies Press, 1998), 36ff.

53. For a discussion of how bypassing persons' "capacities for control over their mental lives" limits their freedom, see Alfred R. Mele, Autonomous Agents: From Self-Control to Autonomy (New York: Oxford University Press, 1995), 166f.

54. Such a law exists, for example, in Germany.

55. I am here assuming that this law is made for the sake of the woman's freedom only and not for the unborn baby. I am also assuming that it is not made to favor one decision over another. To be sure, such a law might be made for other reasons and in particular for the sake of certain outcomes. I am considering the validity of one particular argument for such a law. But most laws that are defended in paternalistic terms can also be justified in other terms.

56. As Elster points out, this is what distinguishes action in the "forum" from market behavior; "The Market and the Forum," 10.

57. This is the view of validity underlying Habermas's model of deliberative democracy; see Habermas, Between Facts and Norms, esp. 104ff.

58. From my argument it follows that the legislation would not be paternalistic if the subjects were convinced of its justifiability.

59. In the history of political thought, it is confusing to see Rousseau's clearly modern idea of popular sovereignty identified with the liberty of the ancients.

60. The notion of freedom as status comes from the republican tradition; cf. David Miller, "Introduction" in Liberty, ed. David Miller (Oxford: Oxford University Press), 1-20; and Tim Gray, Freedom (Houndmills: Macmillan, 1991), 46ff. Philip Pettit's conception of freedom as nondomination is also a status conception; Pettit, Republicanism: A Theory of Freedom and Government (Oxford: Oxford University Press, 1997); see p. 71, where he speaks of freedom as "intersubjective status."

61. Tim Gray, Freedom, 46. 
62. We find this dimension of freedom in Gutmann and Thompson: "Citizens who have effective opportunities to deliberate treat one another not merely as objects who are to be judged by theoretical principles but also as subjects who can accept or reject reasons given for the laws and policies that mutually bind them"; "Democratic Disagreement," in Deliberative Politics, 243-79, at 244. See also Klaus Günther, "Communicative Freedom, Communicative Power, and Jurisgenesis," in Habermas on Law and Democracy: Critical Exchanges, ed. Michael Rosenfeld and Andrew Arato (Berkeley: University of California Press, 1998), 234-54, at 243.

63. Bernard Manin, "On Legitimacy and Political Deliberation," Political Theory 15 (August 1987): 338-68, at 359; see also Bernard Manin, The Principles of Representative Government (Cambridge: Cambridge University Press, 1997), 190.

64. What I have said here is not sufficient to dispel the problem of permanent minorities; that is, the problem of religious, ethnic, or cultural minorities who always find themselves on the losing side when the votes are counted. To secure that such groups are heard, respected, and can become actual participants in self-legislation, certain institutional innovations and new forms of representation might be necessary. This is an important institutional challenge, but unfortunately not one I can go into here.

Christian F. Rostboll is visiting assistant professor at Columbia University (Spring 2005). He is the author of Human Rights, Popular Sovereignty and Freedom (1998) and of articles and book chapters on Arendt, Habermas, deliberative democracy, and autonomy. Currently, he is working on a book manuscript preliminarily titled Deliberative Democracy and Dimensions of Freedom. 